\title{
BRIDGE SMS: Intelligent bridge maintenance and management system
}

\author{
Damir Bekic ${ }^{1}$, Igor Kerin ${ }^{2}$, Panagiotis Michalis ${ }^{3}$, Eamon McKeogh ${ }^{4}$, Paul Cahill ${ }^{5}$, \\ Vikram Pakrashi ${ }^{6}$
}

\author{
DOI: https://doi.org/10.5592/CO/BSHM2017.5.3 \\ ${ }^{1}$ University of Zagreb, Faculty of Civil Engineering (Fra Andrije Kačića-Miošića 26, Zagreb, 10000, \\ Croatia) \\ ${ }^{2}$ MaREI, University College Cork (Beaufort Building, Ringaskiddy, Co. Cork, P43 C573, Ireland) \\ ${ }^{3}$ University of Zagreb, Faculty of Civil Engineering (Fra Andrije Kačića-Miošića 26, Zagreb, 10000, \\ Croatia), \\ ${ }^{4}$ School of Engineering, University College Cork (College Road, Cork, Ireland) \\ ${ }^{5}$ MaREI, University College Cork (Beaufort Building, Ringaskiddy, Co. Cork, P43 C573, Ireland) \\ ${ }^{6}$ Dynamical Systems and Risk Laboratory, School of Mechanical and Materials Engineering and MaREI \\ SFI Centre, University College Dublin (Belfield, Dublin 4, Ireland)
}

E-mails: ${ }^{1}$ damir.bekic@grad.hr; ${ }^{2}$ igor.kerin@ucc.ie; ${ }^{3}$ pmichalis@grad.hr; ${ }^{4}$ e.mckeogh@ucc.ie; ${ }^{5}$ paul.cahill@ucc.ie; ${ }^{6}$ vikram.pakrashi@ucd.ie

\begin{abstract}
An intelligent system for bridge inspection and management requires a knowledge and appreciation of structural engineering, geotechnics, hydraulics, hydrology, materials and transport management. This study introduces BRIDGE SMS, an EU/FP7 project, which couples state-of-the art scientific knowledge in hydrology, river and structural engineering with industrial knowledge in infrastructure management and web-based bridge management. This involves the application of monitoring systems for the assessment and management of the structural and hydraulic vulnerability of infrastructure assets over waterways in an effort to develop an open-source cloud-based intelligent Decision Support System. BRIDGE SMS aims to deliver procedures for complete bridge inspections, through scour and structural inspections, and to develop a reliable decision support tool which would efficiently manage bridge failure risks in a cost-effective way.
\end{abstract}

Keywords: bridge monitoring, risk assessment, flooding, scour risk, infrastructure management

\section{Introduction}

Government agencies, the public and private sectors and professional engineering organizations across Europe need to come together and proactively meet the challenge of creating climate resilient infrastructures (Engineering the Future, 2011). However, water-related hazards associated with extreme precipitation events pose a major threat for the resilience of civil infrastructure over watercourses. Of such hazards, scour is the most complex and challenging water flow and erosion phenomena, leading to structural instability and ultimately catastrophic failures. Scour action is the main cause of bridge failures worldwide (Wardhana, 2003) and has also been identified as highly disruptive and critical in the UK due to its destructive consequences on civil infrastructure systems (Highways Agency, 2009). Such issues are not only confined to onshore locations, as scour and erosion are also considered one of the main complications in the design and operation of offshore infrastructure (Michalis et al., 2013). Despite more resources being invested in protecting structures from waterrelated hazards, future projections indicate that the frequency of extreme flooding across Europe is anticipated to double by 2050 with severe consequences on infrastructure assets (Jongman et al., 2015).

The evaluation of the hydraulic and structural vulnerability (Znidaric et al., 2011) of civil assets over watercourses is a critical issue taking into account the deterioration of the structure as well as the cost and technical and logistical issues arising from rehabilitation or possible replacement of bridges (Michalis et al., 2012; Weninger-Vycudil et al., 2015). One of the main disadvantages of current standards and inspection practices is that, in general, they do not reveal actual riverbed level variations around the foundations of structures due to several issues associated mainly with the actual procedure and frequency of inspections (Michalis et al., 2015). Even though water and flow characteristics around bridge piers have been thoroughly investigated both experimentally and numerically, there is still a lack of a tool that can offer fast and reliable predictions (Valyrakis et al., 2015). Therefore, the implementation of a real-time decision support tool and 
condition monitoring platforms is a highly attractive option required to efficiently manage bridge infrastructure. The importance of a multidisciplinary approach to achieve an effective bridge management system (BMS) through the continual inspection, assessment and maintenance of bridges cannot be overstated. The nature of current BMS is that, most often, emphasis is placed on a single discipline, e.g. structural, and other elements such as hydrologic and scour effects do not receive the attention that is warranted, which can have catastrophic implications on the health of bridge stock, costs and public health.

BRIDGE SMS ${ }^{1}$ addressed such issues by coupling state-of-the art scientific knowledge in hydrology, river and structural engineering with industrial knowledge in infrastructure management and web-based bridge management systems. The project proposes to develop an open-source cloud-based intelligent Decision Support System focusing on, but not limited to, the assessment and management structural and hydraulic vulnerability of bridges over waterways.

The BRIDGE SMS project is built on industry-academia collaborations between University College Cork (UCC), Faculty of Civil Engineering, University of Zagreb (UNIZAG), Cork County Council (CCC), Infraestruturas de Portugal (INFPO) and ARCTIS, a software development company. The BRIDGE SMS project has also established collaboration with the University of Minho (UNIMIN) in Portugal, South Dublin City Council (SDCC), Dublin City Council (DCC) and University College Dublin (UCD) in Ireland, all of which have pledged their support for this project. Collaboration between UCC and UNIZAG evolved as a result of a major railway bridge collapse at Malahide viaduct, the main railway line from Dublin to Belfast, in August 2009 with a passenger service train involved in the incident (McKeogh \& Bekic, 2010a, 2010b, 2010c). UCC and UNIZAG were also involved in the inspection and assessment of scour risk on more than 100 railway bridges in Ireland (Bekic et al., 2012). Recently, a collaboration of some of the authors in UCD, UCC and UMinho, as a part of COST Action TU1406, has analysed thousands of bridge inspections in Cork County, Ireland and of Portugal at a network level (Hanley et al., 2016).

\section{Some considerations on the existing BMS systems}

\subsection{Existing Bridge Management Systems}

Historically, the majority of bridge management systems focuses mainly on structural issues without adequate emphasis on bridge scour risk. An overview of existing bridge management systems, published by the IABMAS Bridge Management Committee assessed a total of 25 Bridge Management Systems (BMS), in operation across 18 countries that are being used to manage 1,000,000 assets (Mirzaei et al., 2014). The report indicated that all BMS show a strong focus on structural health monitoring of bridge structures, managing this aspect of bridge stability to varying degrees.

The IABMAS report (Mirzaei et al., 2014) also highlighted that while the BMS are strikingly similar in their overall approach and operation, there was a lack of standardisation, which meant that systems could not be easily adopted by other agencies. For instance, all BMS, except PONTIS (now AASHTOWare) are used only within the country in which they were developed. The report (p.46) concluded that "a certain level of standardisation could potentially enhance the exchange of knowledge and experience between managing agents, and improve the usefulness of management systems."

One of the key BRIDGE SMS objectives is to provide standardised methods for the assessment of bridge scour risk, which would enable transferability of the bridge management system to different regions and countries. One example of simplifying the standardisation is the introduction of common input data sources (e.g. forecasts, soil moisture, etc.). As a partner of the European Flood Awareness System (EFAS), BRIDGE SMS gives an opportunity to implement common procedures among different organisations.

\subsection{Existing standards for assessment of infrastructure}

Extensive research has been carried out into existing standards worldwide, such as the US DOT, 2001a; US DOT, 2001b; US DOT, 2009; US DOT, 1988; US DOA, 1998; British Railway Board, 1993; The Highways Agency, 2012 in addition to the consideration of other proposed scour risk assessment methods. Such methods include:

a) an assessment based on stability for a stable reference reach and then the departure from stable conditions on an unstable reach of the same stream type (Rogsen, 2001),

\footnotetext{
1 'Intelligent Bridge Assessment Maintenance and Management System', http://www.bridgesms.eu/
} 

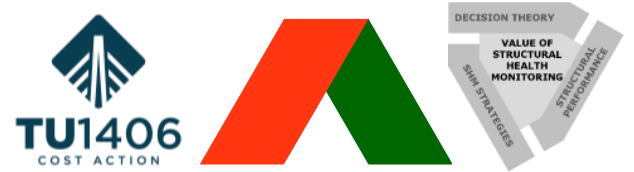

The Value of Structural Health Monitoring for the reliable Bridge Management

b) a diagnostic approach in which the system and its variables are defined, and an evaluation is carried out to assess the causal mechanisms producing the current condition (Montgomery \& MacDonald, 2002), or

c) a simple and brief stability assessment based on sound indicators, supported by photographs and by walking a certain distance upstream and downstream of the project reach (Johnson, 1999).

The existing standards and policies for the evaluation of bridge scour risk have been developed mainly by the US and UK agencies. In the US, three documents on the assessment and management of bridge scour risk have been published (US DOT, 2001a; US DOT, 2001b; US DOT, 2009) together with its own scour assessment programme by the US Department of Agriculture, Forest Service (1998). In the UK, two standards for the assessment of bridge scour risk were published by two agencies: the Railtrack method by British Rail (British Railway Board, 1993) and the Design Manual BA 74/06 by the UK Highways Agency (Highways Agency, 2006) which was replaced by BD 97/12 (Highways Agency, 2012). Other published standards and manuals of EU countries mainly consider the analysis of scour process, the stability of structures in the water and the scour protection measures.

In the study by Bekic et al. (2012) two methods for assessment of bridge scour risk were compared for an identical bridge network, namely the Colorado method (U.S. Department of Agriculture, 1998) and modified BA 74/06 method (Highways Agency, 2006). The comparison of two methods on 100 railway bridges showed that the resulting scour rankings differ for $20 \%$ of bridges with a significant difference of ranking on $10 \%$ of cases. The study also highlighted some drawbacks of the existing evaluation of bridge scour risk. It was identified in several studies (Johnson, 2005; Yanmaz et al., 2007; Bekic et al., 2012) that improvements of the bridge scour assessment methodology could lead to more confident ratings of scour risk and its management.

\section{BRIDGE SMS Methodology and Approach}

BRIDGE SMS will deliver bridge inspection and bridge management methodologies, guidelines and a decision support tool supported by a software platform that empowers engineers and key personnel to predict, identify and prepare for potentially destructive flood events. This will lead to lower maintenance/planning costs and more secured bridge management/operation improving public safety and reducing costs for bridge owners, insurers and maintainers. The proposed system should provide efficient infrastructure management which includes the following:

- decision making, maintenance and mitigation;

- multi-level prioritization list of all structures (bridges);

- inventory about the single structure (name and ID, road / railway line, location, structure type, year of construction, directions on bridge location);

- $\quad$ priority and current status (recommendations based on real-time data from monitoring systems);

- $\quad$ proposed short and medium term works and maintenance;

- $\quad$ easy access to all documents about the structure history and future plans (bridge inspections, comments, reports, pictures, maintenance, construction works, etc.).

The BRIDGE SMS key goals are as follows:

1. Development of standardised methods for bridge scour and structural inspections and bridge management customised to industrial needs.

2. Risk assessment for efficient management of the potential effects of flood events.

3. Development of a database framework which is designed for intuitive use, encouraging participation by personnel at all levels within management authorities.

4. Development and application of low-cost structural health monitoring systems which can deliver realtime key information regarding the impact of water-related hazards at hydraulic structures.

5. Development of a system that:

a. Collects, integrates and processes real-time data at regular intervals from weather and hydrologic sources, meters and gauges, and other sensing devices.

b. will rapidly notify based on in-built intelligence and decision-making processes, relevant personnel of possible maintenance and failure issues.

c. will advise in relation to current Scour Risk at bridge structures and prompt an appropriate Plan of Action (PoA) which may involve various levels of maintenance and repair. 
d. which will be capable of prioritizing and optimizing the operational and maintenance budget costs for infrastructure companies.

6. Maximise the use of new Information and Communications Technology (ICT) hardware such as tablets and cloud-based systems for on-site rapid communications, etc.

As part of the overall development process, a BRIDGE SMS pilot study is underway on the Bandon catchment area in Cork County (Ireland) where bridge scour and flooding issues have been reported over the past decades. It is planned that methodologies and tools developed within BRIDGE SMS project will applied to streams in different geographic regions: (1) region with a history of scour problems based on information from on-site engineers (CCC and INFPO) and a (2) region where the waterways are stable and without scour issues but with potential structural issues.

\subsection{Risk assessment to efficiently manage the potential effects of hydraulic events}

The vulnerability of bridges to failure is generally influenced by two basic factors, the degree of stress or degradation that a bridge can safely withstand and the corresponding severity of the hazardous event required to induce this degree of stress or degradation. Components of the risk determination will involve the product of the estimated probability of failure (including hydrological, hydraulic and geomorphological factors) and the total cost of failure (bridge replacement, loss of life).

The current EU practices on the selection of scour risk management measures include the deterministic and the probabilistic approaches. Deterministic approaches are developed around the risk matrix (Federal Office for Water Management, Switzerland) or the fault tree method (Hoffmans \& Verheij, 1997; Pilarczyk, 1995; Pilarczyk, 1998). In the probabilistic approaches, the risk is evaluated by the probability of bridge failure due an extreme flood event.

BRIDGE SMS aims to effectively assess risks and direct personnel in a more efficient manner with improved inspection standards and the application of technology to accelerate inspections using an intelligent database system to prioritise maintenance tasks. An intuitive, accessible database for cataloguing all available bridge data from multiple experts and sources will make pertinent information easily retrievable as BRIDGE SMS software will provide an automated way of assessing the individual and cumulative risks to the bridge structure. This will also enable timely manner interventions at vulnerable structures and an improved bridge safety and reliability.

The system will allow the integration of external data for efficient decision-making while at the same time adding value to existing data collection services, such as meteorological stations and water level gauges. Collaborations with public and private organisations in Ireland was established (Office of Public Works, Met Éireann, EPA, Waterways Ireland and local authorities) to incorporate meteorological data and hydrological data. Prototype instrumentation viz. a Weather Information Logging Device (WILD) and a Bridge Information Recording Device (BIRD) were developed by the project which will incorporate various sensing technologies applied to pilot bridges to assess their condition (Michalis et al, 2017).

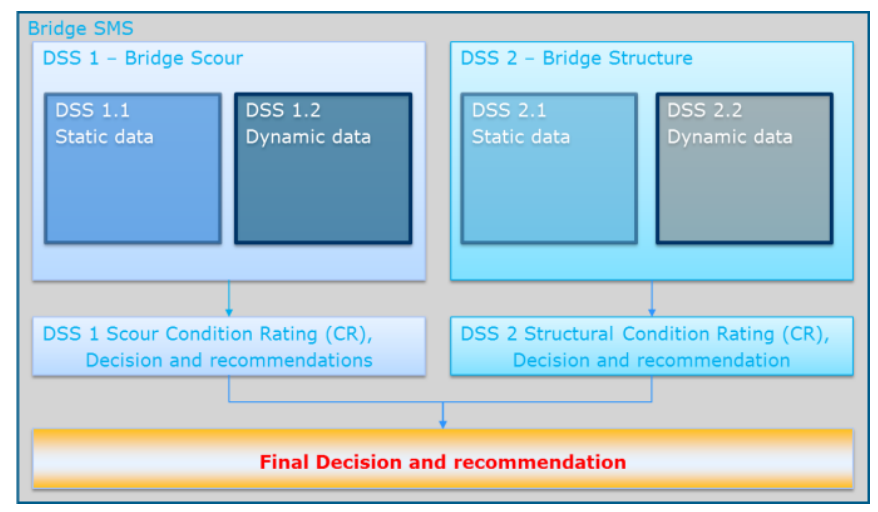

Fig. 1. BRIDGE SMS Decision Support System (DSS)

The Risk Analysis method will form an integral part of the BRIDGE SMS system. The risk of failure will be evaluated through a probabilistic approach. The continuous feedback nature of the BRIDGE SMS system will allow optimisation of risk indices based on real-time monitoring complemented by the catalogued data on assets and historic events.

In order to effectively manage the bridge assets, the project also focuses on preparing a robust cloud-based system consisting of two Decision Support System modules (Structural DSS and Scour DSS). Each module 

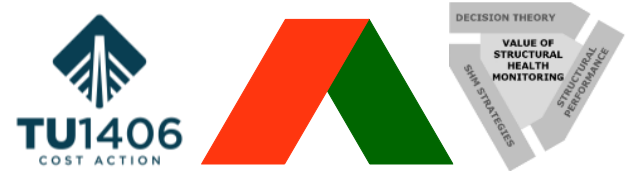

The Value of Structural Health Monitoring for the reliable Bridge Management

Zagreb 2-3 March 2017

operates independently providing an output based on risk indices with the final decision and recommendation deriving from both modules (Fig. 1).

\subsection{Real-time platform for effective bridge management}

Developing the system as a cloud-based platform with mobile and tablet applications reduces platform limitations frequently associated with engineering software. The interface would provide GIS data on the bridges in the BRIDGE SMS database delivering critical real-time information obtained from the BMS, in addition to decisions and recommendations about the condition of the bridge (Fig. 2).

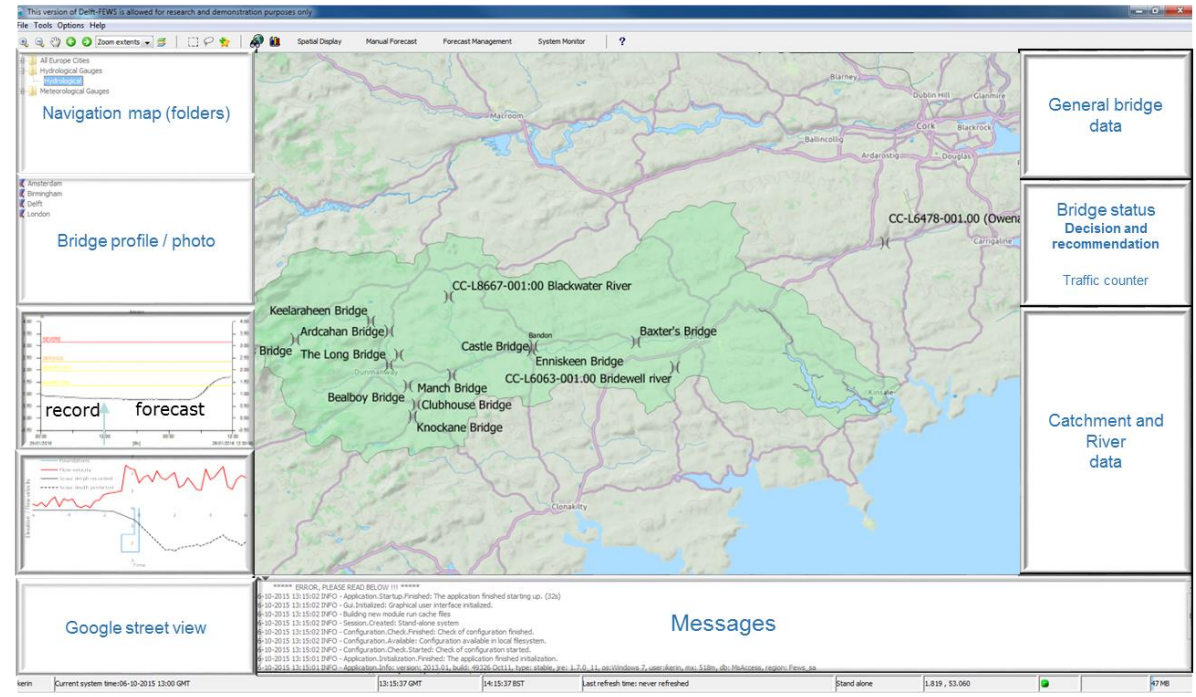

Fig. 2. BRIDGE SMS software interface

The BRIDGE SMS will develop standardised methods for both bridge structural and scour assessment. The BRIDGE SMS platform will also encourage knowledge sharing between agencies, and foster research beyond the specific functionality of a bridge management system. The system will be tested on several networks in collaboration with CCC/INFPO personnel ensuring their relevance and practicality focusing on:

- reaction to events in specific catchment;

- notifications of personnel and improvement of scour management issues.

\section{Conclusions}

Transportation assets represent a critical component of society's infrastructure systems. Flood induced scour is the leading cause of bridge failures worldwide and one of the main climate change impacts on highway and railway infrastructure. The scour process is considered as one of the most complex and challenging water flow and erosion phenomena, leading to a drastic reduction in the safe capacity and stability of structures over water. A large number of bridge structures under a single management unit highlight the need for self-informing system for efficient management of bridge structural, scour and flooding risks. The bridge inspection and management systems are required to integrate knowledge and understanding from multiple fields: hydraulics, hydrology, structural engineering, geotechnics and infrastructure management. However, an absence of similar methodologies for many aspects of bridge inspections and maintenance is identified as one of the major issue of the existing bridge management systems. Limited possibilities for intercomparison of methods and results also limit the potential for further development and testing of various standards in Europe and worldwide.

The BRIDGE SMS EU/FP7 project aims to couple state-of-the art scientific expertise in multidisciplinary engineering sectors with industrial knowledge in infrastructure management. The project will deliver guidelines for complete inspections of bridges over waterways and develop a decision support tool to efficiently manage and prevent flood-related structural failures. This is assisted by the development of standards that could be easily adopted by asset managing organisations, the application of low-cost structural monitoring systems and the development of a software platform that aims to provide key information for cost-effective and timely decisions about the condition of infrastructure. 


\section{References}

Damir Bekić, Eamon McKeogh, Igor Kerin, Stephen Hand and Gillian Bruton. Experiences from Bridge Scour Inspections by Using Two Assessment Methods on 100 Railway Bridges, Proceedings of $2^{\text {nd }}$ International Conference on Road and Rail Infrastructure, Dubrovnik, Croatia, 2012.

British Railways Board. Precautions Against Scour Action on Structures, Handbook 47, Revision A, Group Standards, MacMillan House, Paddington, U.K., 1993.

Engineering the Future. Infrastructure, Engineering and Climate Change Adaptation -ensuring services in an uncertain future, London: The Royal Academy of Engineering, February 2011.

Federal Office for Water Management. Flood Protection: A Common Goal for Federal, Cantonal and Municipal Authorities, Bienne, Switzerland.

Ciarán Hanley, Jose Matos, Denis Kelliher and Vikram Pakrashi. (2016). Integrating multivariate techniques in bridge management systems for life-cycle prediction. Civil Engineering Research Ireland (CERI) 2016, Galway, Ireland.

Gijsbertus J.C.M. Hoffmans and Henk J. Verheij. Scour Manual, Rotterdam, Netherlands; Brookfield, VT : A.A. Balkema, 1997.

Peggy A. Johnson, Gary L. Gleason and Richard D. Hey. Rapid assessment of channel stability in vicinity of road crossing. Journal of Hydraulic Engineering, 1999.

Peggy A. Johnson. Preliminary Assessment and Rating of Stream Channel Stability near Bridges. Journal of Hydraulic Engineering, 131(10), 845-852, 2005.

Brenden Jongman, Stefan Hochrainer-Stigler, Luc Feyen, Jeroen C.J.H. Aerts, Reinhard Mechler, Wouter J.W. Botzen, Laurens M. Bouwer, Georg Pflug, Rodrigo Rojas and Philip J. Ward. Increasing stress on disaster risk finance due to large floods. Nature Climate Change, 4, 264-268, 2014.

Alfred Weninger-Vycudil, Ciarán Hanley, Stefan Deix, Alan O’Connor and Vikram Pakrashi. (2015). Cross-Asset Management for Road Infrastructure Networks. Proceedings of the Institution of Engineers - Transport, 168(5), 442-456

John Kattell and Eriksson Merv. Bridge Scour Evaluation: Screening, Analysis and Countermeasures, USDA Forest Service, Sept. 1988.

Zanyar Mirzaei, Bryan T. Adey, Paul Thompson and Leo Klatter The IABMAS bridge management committee overview of existing bridge management systems - Report by the IAMBAS Bridge Management Committee. International Association for Bridge Maintenance and Safety (IABMAS), 2014.

Eamon McKeogh and Damir Bekic. Malahide Viaduct Reinstatement, Technical Paper 1, Collapse Mechanism and Initial Emergency Works, Flood Study Group University College Cork, 2010a.

Eamon McKeogh and Damir Bekic. Malahide Viaduct Reinstatement, Technical Paper 2, Physical Models, Flood Study Group University College Cork, 2010b.

Eamon McKeogh and Damir Bekic. Malahide Viaduct Reinstatement, Technical Paper 3, Computer Models and Hybrid Modelling. Flood Study Group University College Cork, 2010c.

Panagiotis Michalis, Paul Cahill, Igor Kerin, Hrvoje Solman, Damir Bekic, Eamon McKeogh and Vikram Pakrashi. Wild Bird for Real-Time Assessment of Hydro-Hazards at Bridge Structures. In International Symposium on HydroEnvironment Sensors and Software, pages 1-7, Madrid, Spain, 2017.

Panagiotis Michalis, Mohamed Saafi and Martin D. Judd. Integrated Wireless Sensing Technology for Surveillance and Monitoring of Bridge Scour. In Proceedings of the 6th International Conference on Scour and Erosion, pages 395-402, France, Paris, 2012.

Panagiotis Michalis, Mohamed Saafi and Martin D. Judd. Capacitive sensors for offshore scour monitoring. Proceedings of the ICE - Energy, 166 (4), 189-197, 2013.

Panagiotis Michalis, Alessandro Tarantino, Christos Tachtatzis and Martin D. Judd. Wireless monitoring of scour and redeposited sediment evolution at bridge foundations based on soil electromagnetic properties. Smart Materials and Structures, 24 (12), 1-15, 2015.

David R. Montgomery and Lee H. MacDonald. Diagnostic approach to stream channel assessment and monitoring. Journal of American Water Resource Association, 38 (1), 1-16, 2002.

Krystian W. Pilarczyk. Design Tools Related to Revetments Including Riprap, River, Coastal and Shoreline Protection: Erosion Control Using Riprap and Armourstone, John Wiley \& Sons, pp. 17-38, 1995.

Krystian W. Pilarczyk. Dikes and Revetments: Design, Maintenance, and Safety Assessment, Hydraulic Engineering Division of the Rijkswaterstaat, A.A. Balkema, Rotterdam, Brookfield, 1998.

David L. Rosgen, A stream channel stability assessment methodology, Wildland Hydrology (http://www.u-sc.org/html/documents/streamstability.pdf), Pagosa Springs 2001. 

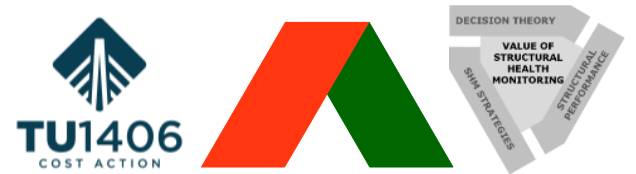

The Value of Structural Health Monitoring for the reliable Bridge Management

The Highways Agency. Assessment Of Scour At Highway Bridges, Design Manual For Roads And Bridges BA 74/06, Aug 2006.

The Highways Agency. Climate Change Adaptation Strategy and Framework. Available online at http://assets.highways.gov.uk/about-us/climate-change/CCAF_Strategy_and_Vol_1_Rev_B_Nov.pdf, 2009.

The Highways Agency. The Assessment of Scour and Other Hydraulic Actions at Highway Structures, Design Manual For Roads And Bridges, BD 97/12, May 2012.

U.S. Department of Agriculture - Forest Service. Bridge Scour Evaluation: Screening, Analysis \& Countermeasures, 1998.

U.S. Department of Transportation - Federal Highway Administration. Evaluating Scour At Bridges, Fourth Edition, Hydraulic Engineering Circular 18, 2001a.

U.S. Department of Transportation - Federal Highway Administration. Stream Stability at Highway Structures, Third Edition, Hydraulic Engineering Circular 20, 2001b.

U.S. Department of Transportation - Federal Highway Administration. Bridge Scour and Stream Instability Countermeasures: Experience, Selection, and Design Guidance-Third Edition, Hydraulic Engineering Circular 23, 2009.

U.S. Department of Transportation, Federal Highway Administration. Scour at Bridges, Technical Advisory T5140.20, 1988

Manousos Valyrakis, Panagiotis Michalis and Hanqing Zhang. A new system for bridge scour monitoring and prediction. In Proceedings of the 36th IAHR World Congress, pages 1-4, The Hague, the Netherlands, 2015.

Kumalasari Wardhana, and Fabian C. Hadipriono, Analysis of Recent Bridge Failures in the United States, Journal of Performance of Constructed Facilities, 17(3), 144-150, 2003.

Melih A. Yanmaz, Alp Caner and Aysu Berk, Renovation of a Safety-Inspection Methodology for River Bridges, Journal of Performance of Constructed Facilities, 21(5), 382-389, 2007.

Ales Znidaric, Vikram Pakrashi V, Alan O' Connor and Eugene OBrien. (2011). A Review of Road Structure Data in Six European Countries. Proceedings of the ICE, Journal of Urban Design and Planning, 164(4), 225-232.

\section{Acknowledgements}

The authors wish to acknowledge the financial support of the European Commission, through the Marie-Curie Marie Curie Industry-Academia Partnership and Pathways Network BRIDGE SMS - "Intelligent Bridge Assessment Maintenance and Management System” (BRIDGE SMS) (FP7-People-2013-IAPP- 612517). 